\title{
Characterization and Microstructural Evolution of WC-Co Cemented Carbides
}

\author{
Hassiba Rabouhi ${ }^{1 *}$, Youcef Khelfaoui ${ }^{2}$, Abdelkrim Khireddine ${ }^{1}$ \\ ${ }^{1}$ Faculty of Technology, University of Bejaia, Road of Targa Ouzemmour, Bejaia 06000, Algeria \\ ${ }^{2}$ Mechanics, Materials \& Energy Laboratory (L2ME), Faculty of Technology, University of Bejaia, Bejaia 06000, Algeria
}

Corresponding Author Email: hassiba.rabouhi@univ-bejaia.dz

https://doi.org/10.18280/acsm.450308

Received: 20 May 2021

Accepted: 23 June 2021

\section{Keywords:}

sintering, hot isostatic pressing, WC-Co cemented carbide, hardness, microstructure, density

\begin{abstract}
Two types of cemented carbides have been elaborated from three mixtures of WC and Co powders containing 3, 5 and $6 \%$ of cobalt mass. Three samples of these mixtures have been obtained by liquid phase sintering and three others of the same composition have been sintered then densified by hot isostatic pressing (HIP). Observations by scanning electronic microscope have allowed to note that the samples elaborated by sintering followed by an HIP densification have a more homogeneous structure than that observed in the sintered samples. Under the compression, the WC grains flattens and interlock more easily from one another which gives a uniform surface appearance. Energy dispersion analysis shows that these samples contain a very small voluminal fraction of graphite and residual porosities, these are more pronounced in sintered samples, especially in the case of alloys with a low Co content (3 and 5\%). X rays diffraction analysis allowed to show clearly the existence of cobalt type carbide in the sintered samples. Measurement of the closed porosity allows to observe that the sintering process followed by densification by HIP leads to the elaboration of alloys with a low rate of closed porosity. Microhardness of these samples have improved hardnesses.
\end{abstract}

\section{INTRODUCTION}

WC-Co cemented carbides are characterized by a unique combination of mechanical and chemical properties. Among these remarkable properties sought after for a large number of industrial applications we have: high compressive strength associated with good behavior against abrasion, high hardness, good dimensional stability, high modulus of elasticity, resistance on impact, appreciable toughness and ultimately good corrosion resistance [1,2].

Users exploit these good properties of these WC-Co cemented carbides for the machining of materials (metallic and non-metallic), woodworking, or even the cutting or blasting of rocks. Such materials are most suitable for cutting tools and drilling tools [3, 4].

These alloys (cemented carbides) are produced by powder metallurgy [5]. The process most often used is sintering with a liquid phase [6-8]. However, the products obtained are not very dense, especially for the low volume fractions of the binder [9]. This results in a limitation and a dispersion of the mechanical characteristics of the material thus obtained [10].

The aim of this work is the search for an innovative solution in some fields of exploitation which consists in going towards other ways of densification of WC-Co mixtures to optimize the mechanical properties of these cemented carbides with low cobalt content.

To get closer to the desired solution, our choice fell on the hot isostatic pressing (H.I.P) densification process [11, 12].

The use of the H.I.P method consist in improving the densification and the microstructure and mechanical properties for this material $[13,14]$. Therefore the decrease in the residual porosity an the inclusion of carbon improves the homogeneity of the final product which improves the mechanical properties of the material [15].

As part of this work two types of tungsten carbides containing 3,5 , and $6 \%$ by weight of cobalt were elaborated by liquid phase sintering, their properties are compared with those of samples sintered than densified by hot isostatic pressing (HIP).

\section{EXPERIMENTAL METHOD}

The preparation of $\mathrm{WC}$ and Co powders took place in the laboratory of the ERIS industrial unit in Batna (Algeria). Cobalt powder is prepared by reduction with hydrogen at $800^{\circ} \mathrm{C}$ of cobalt oxide.

Tungsten powder is made by reducing tungsten trioxide at $750^{\circ} \mathrm{C}$ in a fluidized bed of hydrogen. The carburization of the tungsten grains is carried out using a predetermined amount of carbon black to obtain a WC powder of stoichiometric composition. The W-C mixing is done in a ball mill. It is then placed in graphite boats swept by a continuous flow of hydrogen in an oven where the temperature must be between 1350 and $1500^{\circ} \mathrm{C}$.

The mixing of WC and Co powders is made by wet grinding in order to optimize homogenization. The obtained product is dried to form a two-component powder, a mixture of $\mathrm{WC}$ and Co, which will be used to elaborate WC-Co composites. WC and Co powders grains sizes are less than $5 \mu \mathrm{m}$.

Powder mixtures sintering is prepared under hydrogen atmosphere in three steps.

In a first stage, the mixture is brought to a temperature of $800^{\circ} \mathrm{C}$ for four hours to remove the binder used for shaping the 
samples by cold uniaxial compression. During this step, before reaching the sintering bearing temperature, the first contacts between the particles are created and the necks begin to grow which leads to a reduction in interfacial energy of more than $50 \%$ and low densification

During the second step, the temperature is gradually increased from $800^{\circ} \mathrm{C}$ to $1450^{\circ} \mathrm{C}$ for two hours to bind the WC grains with melted Co. This experience lasts two hours and get a gradual enrichment of cobalt from $1280^{\circ} \mathrm{C}$ on, according to the WC-Co equilibrium diagram [16].

The third rise in temperature is the agglomeration step with liquid phase. The temperature is increased to $1450^{\circ} \mathrm{C}$ to melt cobalt.

A HIP 6 type press is used for HIP tests at Pprime Institute, Poitiers (France). H.I.P is used to densify and to form powders. We obtain massive metal pieces of sizes and shape more or less complex and whose microstructure is uniform and controlled. In our case, this process consists in submitting a previously sintered material to heat treatment under hot isostatic pressure, the pressure can reach $400 \mathrm{MPa}$ and the temperature $2000^{\circ} \mathrm{C}$. The pressure is applied via an inert gas (Argon or Nitrogen) to the material. Under the simultaneous action of pressure and temperature, the material redensifies to form again a solid whose density is close to the theoretical value. In the liquid phase sintering process, one of the constituents of the powder mixture changes to the liquid phase. However, solid phase densification can also occur. Once the phase reaches the lower melting point it becomes liquid, the grain rearrangement step is activated. Which then generates, an adjustment of the shape, the grains which leads to a significant elimination of the pores. Finally, during the last step, microstructural growth is observed, during which the average grain and pore size continuously increases.

In contrary sintering, H.I.P allows densification at lower temperature thus limiting the magnification of grains, hence the interest in developing materials with improved properties. In fact, the applied stresses activate the diffusion at the level of the particulate contacts at relatively low temperatures compared to sintering in the liquid phase, which can cause plastic deformation. The dislocations thus created generate an increase in the internal energy stored and further accelerate the phenomena of diffusion.

\section{EXPERIMENTAL RESULTS AND DISCUSSION}

The morphological study was conducted by electron microscopy in backscattered electron-mode. The surfaces of the materials were prepared by mechanical polishing in succession to the diamond paste of 10 to $0.25 \mu \mathrm{m}$. Considering the size of the WC grains, the micrographs presented below were all realized at a magnification of 4500 to 5000

The micrographs in Figure 1 represent the structures observed in the samples obtained by liquid phase sintering of mixtures of powders of tungsten carbide and cobalt. The micrographs in Figure 2 correspond to the structures observed in the sintered samples, followed by densification by hot isostatic pressing.

The micrographs in Figure 1 show that the deformation of the WC grains is less easy realized, moreover the faceted grains interlock more difficultly with each other, which has the consequence of forming a much less uniform surface with open porosities more and more obvious especially, in the case of samples with low Co content (3 and 5\%).

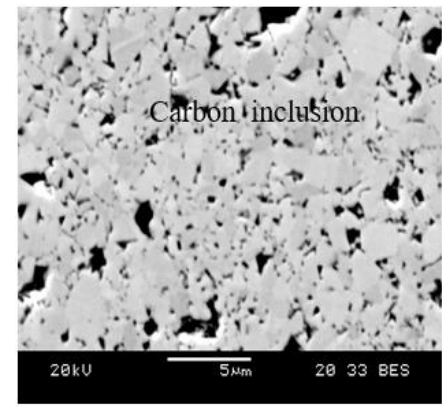

$\mathrm{WC}-3 \% \mathrm{Co}$

(a)

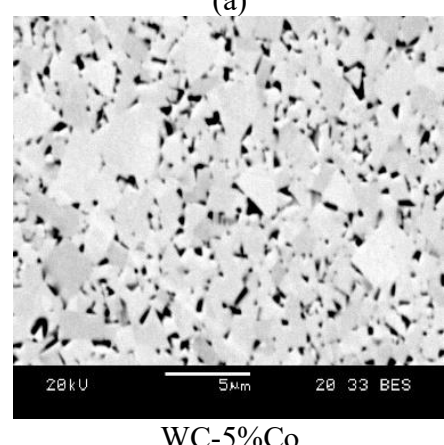

(b)

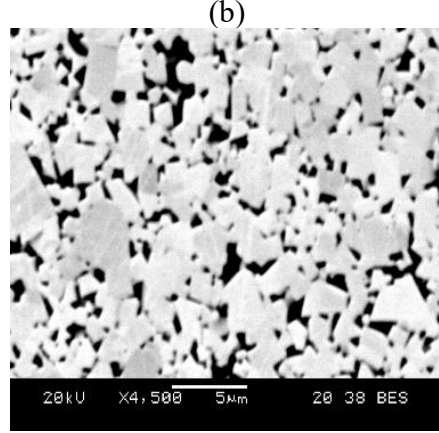

$\mathrm{WC}-6 \% \mathrm{Co}$

(c)

Figure 1. Microstructures observed in samples obtained by liquid phase sintering at $1450^{\circ} \mathrm{C}$

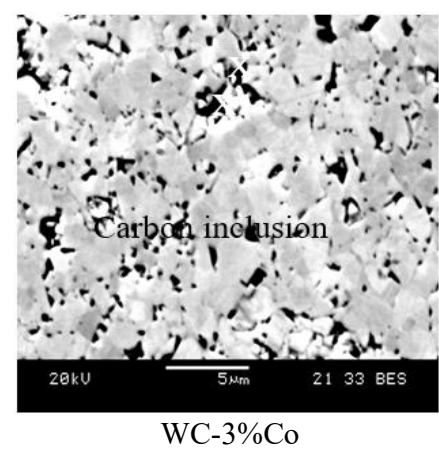

(a)

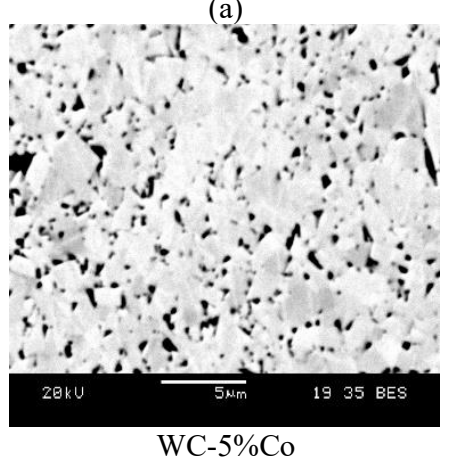

(b) 


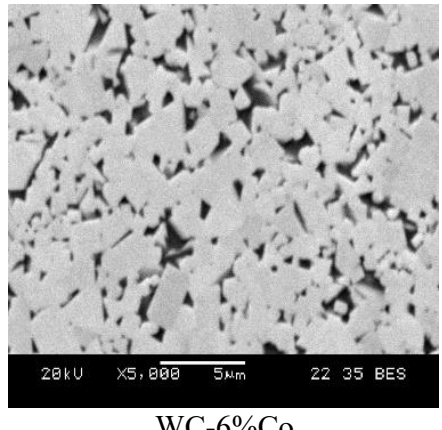

(c)

Figure 2. Microstructures observed in the sintered samples, followed by densification by $\mathrm{HIP}$ at $1450^{\circ} \mathrm{C}$

It is noted, however, that WC grains flattened under compression (Figure 2). They also seem to have quite easily slipped relative to each other in order to best fill the space, giving the most uniform surface appearance of the entire series of samples. However, it is found that the tungsten carbide grains are very fine and difficult to distinguish with sizes less than or equal to one micrometer. Note that these grains develop in two shades, one in light gray and the other in darker shade.

Microscopic observations revealed residual carbon inclusions in the samples obtained by liquid phase sintering. They may correspond to the residual graphite remaining after the carburizing step or to the carbon which forms by precipitation during the duration of the sintering operation. On the other hand, it is noted that the volume fraction of these inclusions is very low in the sintered samples followed by densification by H.I.Pand it is almost non-existent in the samples containing 5 and $6 \%$ by weight of cobalt.

To distinguish the residual porosity from the possible inclusions of graphite, we realized an energy dispersion analysis on an area of the sample WC-3\% Co elaborated by liquid phase sintering. The results obtained are represented by the cartography of Figure 3.

The simultaneous presence of porosity and inclusions of graphite is noted. The samples sintered and densified by H.I.P have a low volume fraction of graphite and residual porosities. Therefore, the amount of cobalt used is insufficient to completely dissolve residual graphite in cobalt despite the high pressure applied.

Indeed, during the rise in temperature and pressure, interdiffusion zones develop at the level of the contacts between the WC and Co grains and are gradually enriched in tungsten and carbon as well as diffusion mechanisms by solid phase. At this point some areas will likely reach critical composition and melt at this processing temperature. Tungsten and carbon diffuse easily if presence of a sufficient quantity of cobalt in the liquid phase. This phenomenon is explained by the fact that cobalt is carburogenic (great affinity towards carbon) which allows it to fix carbon and thus prevent the formation of graphite. Otherwise, residual graphite may remain in this type of sample.

The identification of the nature of the inclusions is obtained by a qualitative $\mathrm{X}$ analysis by performing an experimental survey targeted at the area indicated by a cross in Figure 2 (a). The spectrum obtained shows that the analyzed inclusion consists essentially of carbon. These inclusions may correspond to the residual graphite which remains after the carburizing step or else to the carbon which precipitates during the sintering operation given that it is an alloy with a low Co content (WC-3\%Co) (see Figure 4).

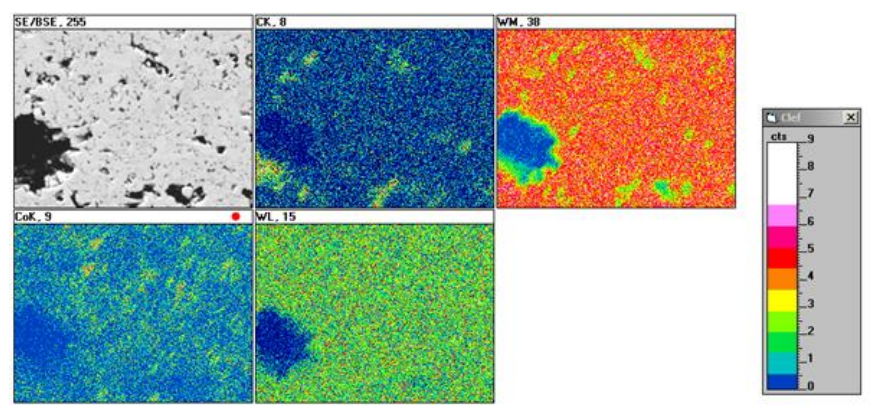

Figure 3. Cartography realized on the mixture WC-3\% Co elaborated by simple sintering

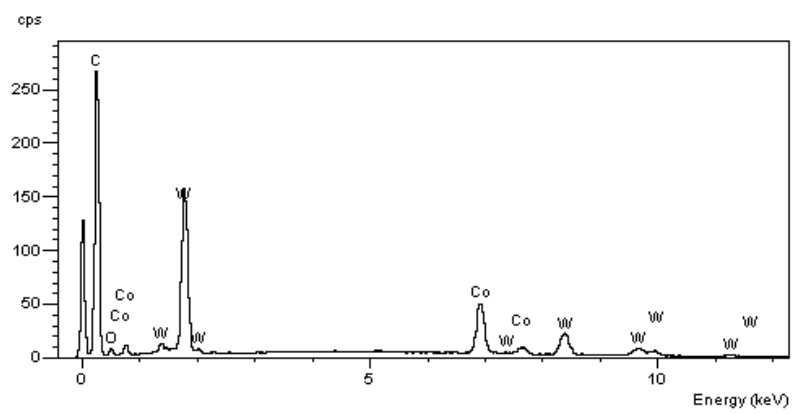

Figure 4. EDS-X analysis spectrum of WC-3\% Co sintered, followed by densification by H.I.P at $1450^{\circ} \mathrm{C}$

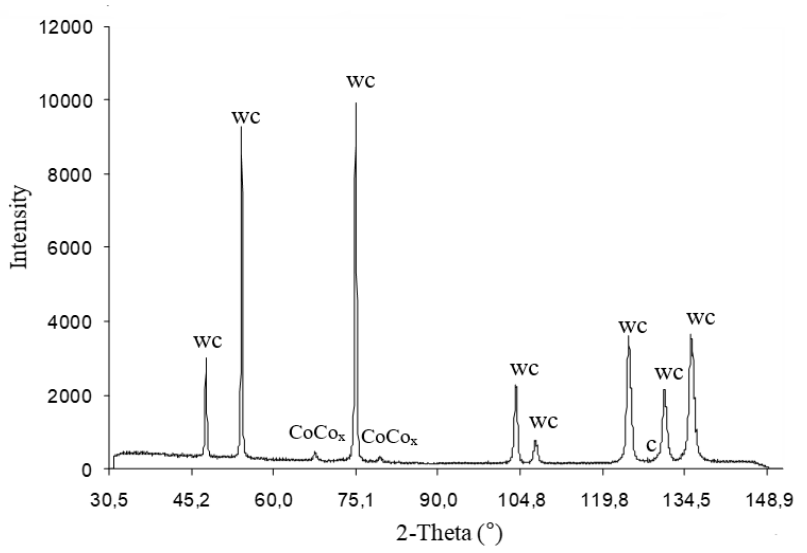

(a)

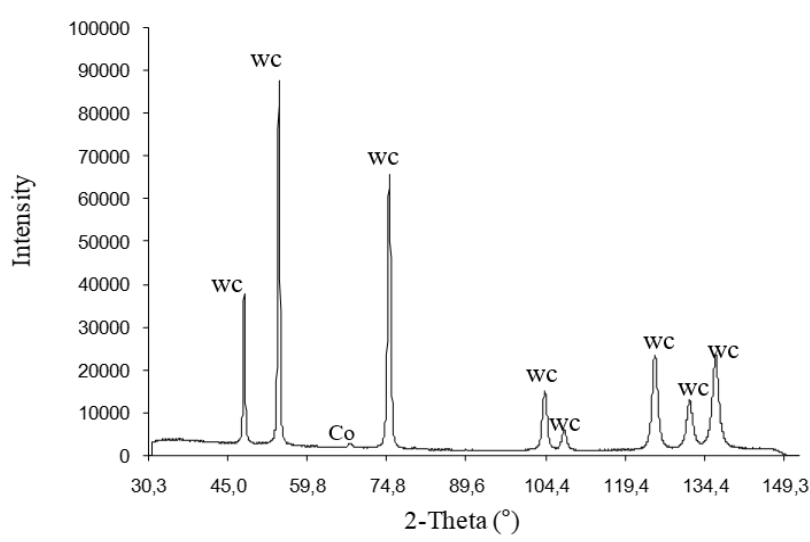

(b)

Figure 5. X-ray diffraction spectrum of WC-6\% Co sample: $\mathrm{a} /$ sintered $\mathrm{b} /$ sintered followed by densification by CIC 
X-ray diffraction analysis was used in order to identify the different phases contained in the alloys. The characteristic spectrum of both types of samples are shown in Figure 5. Xray diffraction analysis allows to demonstrate the existence of cobalt-type carbide in the sintered samples.

The measurement of the theoretical or true density of the raw or compacted powders was carried out on a helium pycnometer. The principle consists of measuring the volume occupied by the known mass samples. The use of helium has two advantages: it penetrates the microporosities of the order of a few angstroms and behaves like a perfect gas. The closed porosity of each sample is obtained from the difference between the theoretical density $\rho_{t h}$ of the WC-Co mixture and that of the measured density $\rho_{m}$ by helium pycnometer on the samples. The samples were tested eight times in succession; the given costing is the average of the eight different experimental results. The amount of closed porosity is given by the following relationship: $\varepsilon_{C}(\%)=100 . \frac{\rho_{t h}-\rho_{m}}{\rho_{t h}}$ and the results obtained are shown in Table 1.

Table 1. Closed porosity rate in both types of elaborate alloys

\begin{tabular}{ccccccc}
\hline Samples & \multicolumn{2}{c}{ Sintering } & \multicolumn{4}{c}{$\begin{array}{c}\text { Sintering followed by } \\
\text { densification by H.I.P }\end{array}$} \\
\hline & $\rho_{t h}$ & $\rho_{m}$ & $\begin{array}{c}\varepsilon_{C} \\
(\%)\end{array}$ & $\rho_{t h}$ & $\rho_{m}$ & $\begin{array}{c}\varepsilon_{C} \\
(\%)\end{array}$ \\
\hline WC-3\%Co & 15.16 & 14.245 & 6.03 & 15.16 & 14.915 & 1.61 \\
\hline WC-5\%Co & 14.946 & 14.436 & 3.41 & 14.946 & 14.946 & 0.34 \\
\hline
\end{tabular}

The results obtained show that for the same cobalt content, the sintered alloys, followed by a densification by H.I.P, have a closed porosity rate much lower compared to those obtained by conventional sintering. It is noted that this porosity rate decreases with the increase of the cobalt content in both types of samples.

This is due to pressure sintering mechanisms such as plastic deformation, creep, and diffusion material transport mechanisms which cause stirring and diffusion welding of the WC grains in contact.

Microhardness tests were performed on both types of samples. The hardness determines both the resistance of the material to abrasion and wear. It is at the same time according to the cobalt content and the size of the WC grains [17]. In cemented carbides the hardness is measured by pyramidal diamond indentation tests (Vickers hardness, HV). This type of test is carried out on polished flat surfaces with loads of 500 $\mathrm{kg}$.

The set of results relating to the tests carried out is presented in Table 2.

Table 2. Micro harnesses of the three types of alloys produced

\begin{tabular}{ccc}
\hline Samples & $\begin{array}{r}\text { sintering at } \\
\mathbf{1 4 5 0}^{\circ} \mathbf{C}\end{array}$ & $\begin{array}{c}\text { Sintering followed } \\
\text { by densification } \\
\text { by HIP at } \mathbf{1 4 5 0}^{\circ} \mathbf{C}\end{array}$ \\
\hline WC-3\%Co & 1279 & 1444 \\
WC-5\%Co & 1448 & 1704 \\
WC-6\%Co & 1590 & 1600 \\
\hline
\end{tabular}

The results obtained show that the process of densification by sintering followed by densification by H.I.P allows to obtain cemented carbides WC-Co with improved mechanical properties compared with those elaborated by conventional sintering.

\section{CONCLUSIONS}

In the context of this work, we sought to optimize the homogeneity of cemented carbides by densification of basic mixtures by hot isostatic pressing. This powerful process is used to elaborate WC-Co cemented carbides with high performance mechanical properties. The comparative study of the properties of cemented carbides obtained by the two techniques: liquid phase sintering and sintering followed by densification by H.I.P could be realized.

Microstructural characterization by scanning electron microscopy allowed us to compare the microstructures of the samples elaborated by liquid phase sintering with those of the sintered samples, followed by densification by H.I.P. The tungsten carbide grains appear homogeneously distributed in the sintered samples followed by densification by H.I.P. The samples elaborated by conventional sintering are characterized by a non-homogeneous distribution of the carbide phase. Indeed, there are zones in the form of clusters of WC and Co grains.

These samples also contain isolated inclusions of residual graphites formed by decarburization during the sintering process and also contain residual porosity in significant quantities, especially in samples with low cobalt content (3 and $5 \%$ ). This level of porosity is lower in the sintered samples, followed by densification by H.I.P.

$\mathrm{X}$-ray diffraction analysis revealed the existence of cobalttype carbide in samples elaborated by conventional sintering. The mechanism of dissolution precipitation is probably at the origin of the appearance of this phase. The long duration of liquid phase sintering treatment favors this phenomenon. The WC grains dissolve and the released carbon atoms diffuse through the liquid phase and react with Co to form a new cobalt carbide phase. The measurement of the closed porosity with helium pycnometer allows to observe that the sintering process followed by densification by H.I.P leads to the elaboration of alloys with a low rate of closed porosity compared to those obtained by conventional sintering.

The determination of mechanical properties was made from Vickers microhardness tests. It is found that the microhardness is significantly higher in the sintered samples, followed by densification by H.I.P. the improvement of the microhardness is certainly due to the homogeneity of the distribution of the binder phase in this type of samples.

In the future it will be interesting to use nanometric powders of WC to optimize the parameters of cycles H.I.P.

\section{REFERENCES}

[1] Pastor, H. (1984). Fabrication et propriétés d'utilisation des cermets carbure de tungstène-cobalt -prospective dans le domaine de la coupe. Matériaux et Techniques, 72(12): 433-450. https://doi.org/10.1051/mattech/198472120433

[2] Guo, J., Fang, Z.Z., Fan, P., Wang, X. (2011). Kinetics of the formation of metal binder gradient in $\mathrm{WC}-\mathrm{Co}$ by 
carbon diffusion induced liquid migration. Acta Materialia, $\quad$ 59(11): 4719-4731. https://doi.org/10.1016/j.actamat.2011.04.019

[3] Wu, Z., Deng, J.X., Xing, Y.Q., Cheng, H.W., Zhao, J. (2012). Effect of surface texturing on friction properties of WC/Co cemented carbide. Materials \& Design, 41: 142-149. https://doi.org/10.1016/j.matdes.2012.05.012

[4] Xu, P.Q. (2011). Dissimilar welding of WC-Co cemented carbide to $\mathrm{Ni}_{42} \mathrm{Fe}_{50.9} \mathrm{C}_{0.6}-\mathrm{Mn}_{3.5} \mathrm{Nb}_{3}$ invar alloy by laser-tungsten inert gas hybrid welding. Materials \& Design, $32(1)$ 229-237. https://doi.org/10.1016/j.matdes.2010.06.006

[5] Trent, E.M. (1984). Metal Cutting. Butters Worths, Boston $\quad 2^{\text {nd }} \quad E d$ https://doi.org/10.1080/00207548408942509

[6] Chaix, J.M. (1993). le frittage en phase liquide, in chimie physique du frittage. Hermès: Paris, pp. 251-283.

[7] Kieffer, R., Benesovsky, F. (1965). Hartmetalle. Springer-Verlag, Wien. https://doi.org/10.1007/978-37091-8127-0

[8] Dubois, J., Mai, C., Riviere, R. (1974). Influence de la température de frittage et des conditions de refroidissement sur la texture et les contraintes résiduelles dans les alliages cémentés WC-Co. Zeitschrift fuer Metallkunde, 65(2): 130-135. https://doi.org/10.1515/ijmr-1974-650208

[9] Mchugh, P.E., Riedel, H. (1997). A liquid phase sintering model: Application to $\mathrm{Si}_{3} \mathrm{~N}_{4}$ and WC-Co. Acta Materialia, 45(7): 2995-3003. https://doi.org/10.1016/S13596454(96)00378-3

[10] Liu, Y., German, R.M. (1996). Contact angle and solidliquid-vapor equilibrium. Acta Materialia, 44(4): $1657-$ 1663. https://doi.org/10.1016/1359-6454(95)00259-6

[11] Kuczynski, G.C. (1949). Self-diffusion in sintering of metallic particle. Self-Diffusion in Sintering of Metallic Particles. In: Sōmiya S., Moriyoshi Y. (eds) Sintering Key Papers. Springer, Dordrecht. https://doi.org/10.1007/978-94-009-0741-6_33
[12] Kingery, W.D., Berg, M. (1955). Study of the initial stages of sintering solids by viscous flow, evaporationcondensation, and self-diffusion. Journal of Applied Physics, 26: 1205. https://doi.org/10.1063/1.1721874

[13] Kunz, J., Boontanom, A., Herzog, S., Suwanpinij, P., Kaletsch, A., Broeckmannac, C. (2020). Influence of hot isostatic pressing post-treatment on the microstructure and mechanical behavior of standard and super duplex stainless steel produced by laser powder bed fusion. Materials Science and Engineering: A, 794: 139806. https://doi.org/10.1016/j.msea.2020.139806

[14] Dong, D., Xiang, X., Huang, B., Xiong, H., Zhang, L., Shi, K., Liao, J. (2020). Microstructure and properties of WC-Co/CrMnFeCoNi composite cemented carbides. Vacuum, 179: 109571. https://doi.org/10.1016/j.vacuum.2020.109571

[15] Rabouhi, H., Boudrahem, S., Khireddine, A. (2016). Characterization of cemented carbide containing $11 \%$ mass cobalt elaborated by hot isostatic pressing: A study of the reactivity of the steel container with the component WC. Annales de Chimie Science des Matériaux, 40(3-4): 111-120. https://doi.org/10.3166/acsm.40.111-120

[16] Rabouhi, H., Boudrahem, S., Grosbras, M. (2007). Etude comparée des propriétés de carbures cémentés élaborés par frittage et compression isostatique à chaud. Annales de Chimie Science des Matériaux, 32(1): 11-18. https://doi.org/10.3166/acsm.32.11-18

[17] Brookes, K.J.A. (1979). World Directory and Handbook of Hardmetals. Engineer's Digest, Ltd. London.

\section{NOMENCLATURE}

$\begin{array}{ll}\rho_{t h} & \text { theoretical density, } \mathrm{g} / \mathrm{cm}^{3} \\ \rho_{m} & \text { measured density, } \mathrm{g} / \mathrm{cm}^{3} \\ \varepsilon_{C} & \text { rate closed porosity, }(\%)\end{array}$

